\title{
CAN THE TEACHERS OF EARLY CHILDHOOD EDUCATION CONTRIBUTE IN THE EARLY DIAGNOSIS OF THE AUTISTIC SPECTRUM DISORDER?
}

\section{Ana Cristina de Castro $^{1}$ and Silvyo David Araújo Giffoni ${ }^{2}$}

\begin{abstract}
1Pedagogue, expert in Psychopedagogy, specialization in Neuropsychology Applied to Child Neurology- School of Medical Science./ UNICAMP. Address: Anchieta Ave, 636/24 Cambui, Campinas, SP. Brazil zip code 13015-101

${ }^{2}$ Neuropediatrician. Hospital of Clinics-DISAPRE - Research Laboratory on Disorders, Learning Difficulties and Attention Disorders School of Medical Science/ UNICAMP. Address: Vital Brasil st, 251 Cidade Universitária "Zeferino Vaz", Campinas - SP Brazil zip code 13083-888
\end{abstract}

\section{A R T I C L E I N F O \\ Article History: \\ Received $19^{\text {th }}$ June, 2017 \\ Received in revised form $3^{\text {rd }}$ \\ July, 2017 Accepted $18^{\text {th }}$ August, 2017 \\ Published online $28^{\text {th }}$ September, 2017}

\section{Key words:}

Autism Spectrum Disorder, Early Childhood Education, Early Diagnosis.

\begin{abstract}
A B S T R A C T
Aim: The aim of this study was to investigate whether early childhood teachers can contribute to the early diagnosis of Autistic Spectrum Disorder (ASD). This disorder of neurodevelopment arises in the first years of life, characterized by a dyad that involves communication and consequent socialization and on the other hand the presence of repetitive and stereotyped behaviors with repertoire of interests and restricted activities (DSM-5, 2013). In this sense it is necessary to emphasize the pedagogical view of the teachers that attend this age group in which one can observe early characteristics of ASD. To know about the experience of these teachers with Early Childhood Education and with students with ASD, we know the characteristics of the disorder, evaluated by levels of training. Method: 300 teachers from the municipal network of Paulínia, Sao Paulo, Brazil; participated in the research through a specific questionnaire prepared for this purpose. Results: it was evidenced that teachers showed knowledge of the main characteristics of the picture, many students are in the stage of oral language acquisition and atypical characteristics can be observed by teachers. The working time of the interviewed teachers is between 5 and 15 years old or more. Many said they had worked with students with this disorder, pointed out as more important aspects the presence of expert teachers and school with resource rooms with materials adapted to receive these children. Conclusion: with this study it was possible to show that there is a lack of continuous training for teachers, teaching materials and adapted rooms. It should also be noted that if the diagnosis is made in the first 3 years (chronological age in which children are in preschool centers) and with early and long term interventions, there will be a positive impact on the prognosis of the cases.
\end{abstract}

Copyright $₫ 2017$ Ana Cristina de Castro and Silvyo David Araújo Giffoni. This is an open access article distributed under the Creative Commons Attribution License, which permits unrestricted use, distribution, and reproduction in any medium, provided the original work is properly cited.

\section{INTRODUCTION}

Autistic Spectrum Disorder (ASD) is classified according to the diagnostic criteria of the fifth edition of The Diagnostic and Statistical Manual of Mental Disorders DSM-5(2013) as a neurodevelopmental disorder. This disorder is characterized by a dyad that involves communication and consequent socialization and on the other hand the presence of repetitive and stereotyped behaviors with repertoire of interests and restricted activities DSM-5 (2013). Although the etiology is still unknown, several studies have shown evidence of associated epigenetic components, such as the interaction of genes and environment, Rutter (2011) as exposure to chemical components during gestation, Arif et al (2013). This disorder may be present since the 18-month Chronological Age, Charman (2014) and there are no biological markers for

*Corresponding author: Ana Cristina de Castro Pedagogue, expert in Psychopedagogy, specialization in Neuropsychology Applied to Child Neurology- School of Medical Science/ UNICAMP. Address: Anchieta Ave, 636/24 Cambui, Campinas, SP. Brazil zip code 13015-101 this pathology Gadia et al (2004), the diagnosis depends on clinical and interdisciplinary observation Muszcat et al. (2014). The prevalence of the disorder is increasing, but it is discussed to what extent this expansion of the diagnostic criteria in DSM-5 occurs, the methodological differences in the cientific studiesbetter recognition of the disorder by health professionals or whether there is a real increase in frequency (APA, 2013).

Recent data indicate an approximate prevalence of ASD from $0.60 \%$ to $1 \%$ in live newborns. Data from the Centers for Disease Control and Prevention (CDC) point to 1:68 North American live births. In Brazil an epidemiological study found a prevalence of 1 to 368 children aged 7 to 12 years Paula et al (2011) a study published by the CDC in 2014, points to $1: 45$ in the United States, the age group surveyed is 3 to 17 years. In this sense, it should be emphasized that in the age group in which early characteristics of TEA can be observed, children are already in full-time school and are in 
the stage of oral language acquisition and many characteristics can be observed by teachers. In verbal or nonverbal communication, there are children who have difficulty initiating a conversation or looking in the eye, can have repetitive speech, no context, with a monotone voice, speech delay or regression, do not seem to hear or understand what is being said. There are children with ASD who perceive small details, such as the changing place of classroom objects, scents and textures, there are those who assemble jigsaw puzzles with impressive dexterity, and there are others with obsessive ways of playing, such as spinning objects, stack, load.

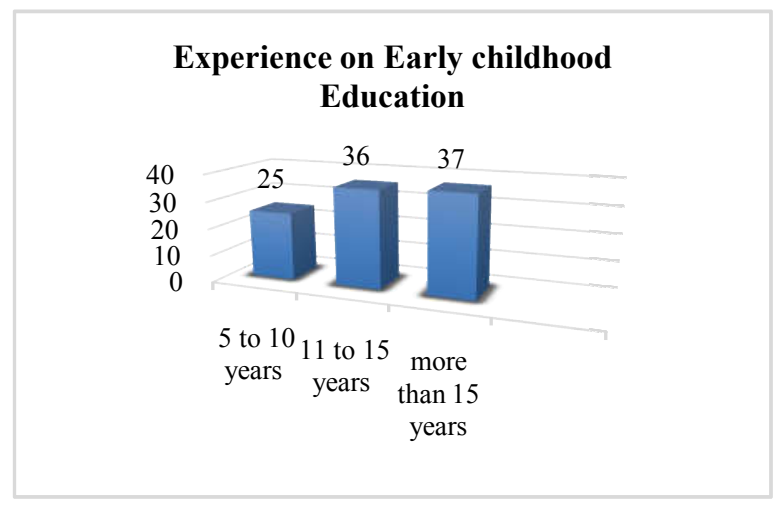

Figure 1

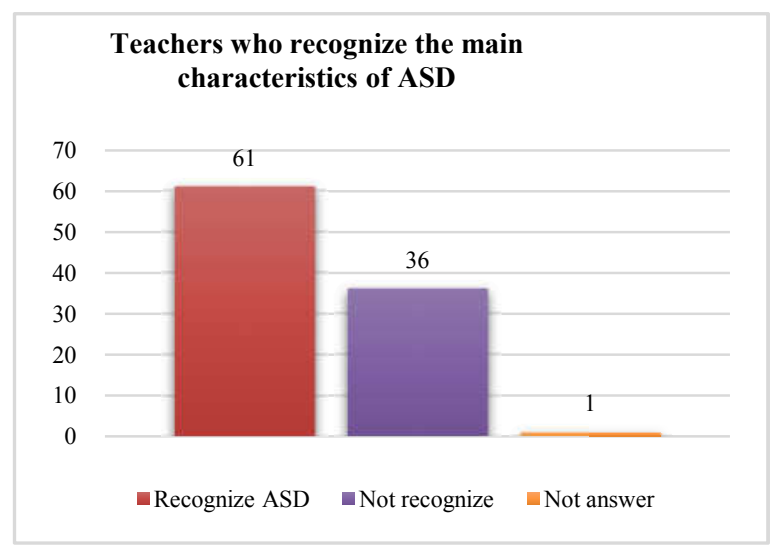

Figure 2

Autistics have great resistance to change, including activities proposed by teachers, places of the room or school, changes in time. The lack of social reciprocity is evidenced by solitary play and improper use of toys, students with ASD do not understand the rules of proposed activities, do not play "pretend", do not understand contexts by facial expressions, Theory of Mind, Frith (1996), stereotypies vary from the flapping movement to complex rituals, Rappin (1997). For the diagnosis of ASD there is a screening instrument frequently used, Checklist for Autism in Toddlers (CHAT), for screening children 16 to 30 months of age, Baron-Cohen et al, 1992). The test is composed of 23 questions that explore the presence of developmental milestones (Baron-Cohen et al. 1996) The Childhood Autism Rating Scale (CARS) is for children older than two years and assesses the intensity of autistic characteristics and there is a way to differentiate children with developmental delay without autism. It has been translated and validated for use in Brazil and its final version is known as CARS-BR, Pereira et al (2008); Rapin et al. (2008). Two new tools have emerged to define the diagnosis of autism that are used mainly in the context of scientific research, namely: The Autism Diagnostic Interview-Revised (ADI-R) and also
The Autism Diagnostic Observation Schedule-General (ADOS-G).

Recent data indicate an approximate prevalence of ASD from $0.60 \%$ to $1 \%$ in live newborns. Data from the Centers for Disease Control and Prevention (CDC) point to 1:68 North American live births. In Brazil an epidemiological study found a prevalence of 1 to 368 children aged 7 to 12 years Paula et al (2011) and a study published by the CDC in 2014, points to $1: 45$ in the United States, the age group surveyed is from 3 to 17 years. In this sense, it should be emphasized that in the age group in which early characteristics of ASD can be observed, children are already in full-time school and are in the stage of oral language acquisition and many characteristics can be observed by teachers. In verbal or nonverbal communication, there are children who have difficulty initiating a conversation or looking in the eye, can have repetitive speech, no context, with a monotone voice, speech delay or regression, do not seem to hear or understand what is being said.

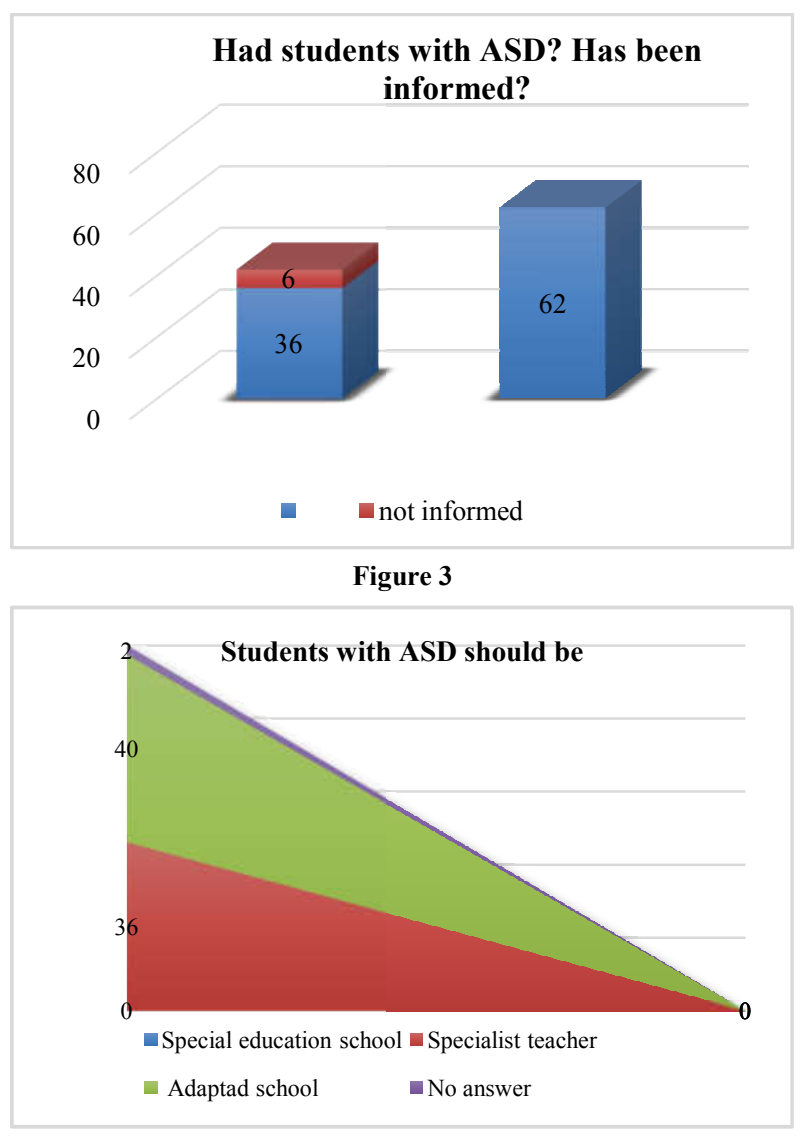

Figure 4

There are children with ASD who perceive small details, such as the changing place of classroom objects, scents and textures, there are those who assemble jigsaw puzzles with impressive dexterity, and there are others with obsessive ways of playing, such as spinning objects, stack, load. Autistics have great resistance to change, including activities proposed by teachers, places in the classroom or school, changes in time. The lack of social reciprocity is evidenced by solitary play and improper use of toys, students with ASD do not understand the rules of proposed activities, do not play "pretend", do not understand contexts by facial expressions, theory of mind, Frith (1996), stereotypies vary from the flapping movement to complex rituals, Rappin (1997). For the 
diagnosis of ASD there is a screening instrument often used, Checklist for Autism in Toddlers (CHAT) for the screening of children aged 16 to 30 months, Baron-Cohen et al (1992). The test is composed of 23 questions that explore the presence of developmental milestones, Baron-Cohen et al. (1996).

The Childhood Autism Rating Scale (CARS) is for children older than two years and assesses the intensity of autistic characteristics and there is how to differentiate children with developmental delay without autism. It has been translated and validated for use in Brazil and its final version is known as CARS-BR Pereira et al (2008); Rapin et al. (2008). Two new tools have emerged to define the diagnosis of autism that are used mainly in the context of scientific research, namely: The Autism Diagnostic Interview-Revised (ADI-R) and also The Autism Diagnostic Observation Schedule-General (ADOS-G). The main comorbidities of ASD are: Intellectual disability $(70-86 \%$ of cases of ASD); ADHD (37-85\%); epilepsy (35\%); eating disorders; genetic syndromes; oppositional-defiant disorder; disorder of coordination development; mood disorder (20\%); tics; schizophrenia, conduct disorder; obsessive compulsive disorder OCD; enuresis; encoprese; disorder sleep (40 to $80 \%$ ); posttraumatic stress syndrome; anxiety disorder (30 to $84 \%$ ); Tourette's syndrome; psychosis, Schwartzman (2011), Rotta et al (2016).

Early identification of ASD in children in the early childhood education stage brings benefits to the child and the family. This includes correct diagnosis, pedagogical support, behavioral and communication oriented interventions, as well as treatment of comorbidities, Dover, Couteur (2006). In order to have a positive impact on the prognosis regarding psychosocial and family adaptation, cognitive performance, adaptive behavior and communication and social interaction skills Virués-Ortega (2010), when social and academic demands have a greater influence on the life of this child. For Vigostsky (2007) the school needs to create tools that can guarantee the full development of any individual, with or without disabilities. In this perspective, it is essential that it knows the mental processes of the subjects in / for the construction of objectives and / or educational programs, capable of potentializing their cognitive functions, Vigotsky, (2007). In this way, as many teachers work with children without the diagnosis of ASD, this was the motivation to investigate the importance of early childhood education teachers in the early diagnosis.

\section{METHOD}

\section{Sample and procedure}

300 teachers from the publics schools of the city of Paulínia, Sao Paulo, Brazil, were invited. The project was submitted to the Human Research Ethics Committee (CEP) of the School of Medical Sciences of the University of CampinasUNICAMP, pursuant to resolution 466/12, approved with the opinion no. $1,278,180$, the beginning of the after the approval of said council. The participation of the teachers was voluntary, through a questionnaire developed exclusively for this purpose, with 2 open and 10 closed questions. Teachers with a high school degree in Teaching, Pedagogues and graduates in the area of Education were participants.

\section{RESULTS}

Of the 300 professors invited to participate in research 98 agreed on respond to the questionnaire, signed the Informed Consent Term. Statistical analysis of the data was done using the Chi-Square, Fisher's Exact Test (TEF) for comparison between groups. The level of significance between groups was $p=0.01$ and the open multiple choice questions were analyzed by the Statistics 21.0 for Windows ${ }^{\circledR}$ Statistical Package for Social Sciences (SPSS) worksheet.

\section{DISCUSSION}

The results show a frequency of $100 \%$ of women working in the units surveyed. A study in Sao Paulo with teachers from regular and special schools showed the perspective of teachers with children and adolescents with ASD in the classroom, lack of knowledge, lack of support from other professionals, Pimentel et al. (2014). In addition there is no continuing education. In this research more than $80 \%$ of the graduate professors count that they looked for in the specialization a way to improve the pedagogical practice. There are no content adequacy study groups to welcome students with any type of disorder or disability. A work done by Spanish researchers point similar information about the importance of the teacher in the early diagnosis Rodriguez et al (2012). In the United States, research indicates that the states where the diagnosis is most precocious are those that invest most in Education and Health. In the interior of Sao Paulo, work similar to this one, evaluated the teaching experience with children with ASD in the work of 38 teachers. They concluded that these were lacking in information and pointed out the need for diffusion of knowledge for teachers with the help of other professionals, Favoretto et al (2014).

Doubts about ASD and Education are not unique to Brazilian Education, in other countries there is also a lack of teacher knowledge about autism. A study in Pakistan about the lack of unknowledge of Early Childhood Teachers about ASD showed that there was a marked improvement in the school performance of students of teachers trained by a manual of resources for teachers dealing with autism. The study emphasizes that adequate teacher training can improve the quality of work with these students. There are proposals for the implementation of diagnostic training programs so that teachers can teach the students according to their needs. In the present study, educator training was seen as important for dealing with students with ASD. However, in spite of this, no significant difference was found between the degree of training and the fact that she felt prepared to deal with students with this disorder, even though she had more time to work with these students. The need to expand and update knowledge about the disorder, exchanges of information and experiences among teachers of the regular network has been evidenced, this supports the idea that theoretical and practical knowledge is necessary for the work, Rodrigues et al (2012). Such data are in agreement with those observed in this research, where similar difficulties were observed in the work with ASD, does not depend on the level of teacher training. Although graduate teachers continue to feel unprepared to deal with ADS, it has changed the way they observe such children differently from others. For these teachers the great challenge in these frameworks is how to aid in early diagnosis. Although many of the teachers are knowledgeable about autism, even with recognized professional skills, most 
feel unprepared for working with students with ASD. Training and working time did not influence, in the present sample, the aspects that they consider important to work with. In this way it can be inferred that the classroom experience with students with ASD is what prepares them for such a challenge. Thus, exchange of experiences, study groups, expert technical guidance for the classroom. All this forms a body that transmits security to the teacher who often perceives changes in behavior in his students, therefore, can aid in diagnosis and intervention precocious. This research brings light to some demands, but further studies are needed to expand knowledge. If the diagnosis is made in the first 3 years (the age at which the children are in the kinderkarten) and with early and long-term interventions, there will be a positive impact on the prognosis, as well as on the family, social and psychological adaptation to cognitive and to adaptive behavior, in communication skills and social interaction Virués-Ortega (2010).

\section{CONCLUSION}

We can conclude that if children attend kindergarten at the age at which it is possible to make an early diagnosis of ASD, it is necessary to have continuous training for the preparation of teachers who receive these students together with other professionals, therefore, despite teachers of Early Childhood Education when their students have atypical development can not point to it and do not participate in early diagnosis. Exchanges of experiences and study groups should involve teachers who are able to point out the neurodevelopmental problems of their students. It is necessary to expand studies and knowledge.

\section{References}

1. Arif M M, Niazy A, Hassan B, Ahmed F, Awareness of autism in primary school, 2013, Pakistan Ziauddin University. Disponível em: http://dx.doi. org/10.1155/ 2013/96155

2. Baron-Cohen S, Allen J, Gillberg, C. Can autism be detected at 18 months? The needle, the haystack, and the CHAT. The British Journal of Psychiatry Dec 1992, 161 (6) 839-843; DOI: 10.1192/bjp.161.6.839

3. CDC-Data and Statistics, Autism Spectrum Disorders [Acesso em. 12/01/2016]. Disponível em: http://www.cdc.gov/features/dsautismdata/index.html

4. Charman T, Early identification and intervention in autism disorders: some progress but not much we hope. Int J Speech Lang Pathol. London, 2014; 16(1): 15-18.

5. Diagnostic and Statistical Manual of Mental Disorders (DSM-5), 2013. Arlington, VA: American Psychiatric Publishing. $5^{\mathrm{a}}$ ed.

6. Dover CJ, Le Couter A, How to diagnose Autism. Arch Dis Child. 2007 Jun; 92(6): 540-545.doi: 10.1136/adc.2005.086280

7. Favoretto N C, Lamônica D A C, Communication performance of children with Autism Spectrum Disorders, Marília, Rev Bras Ed Esp, 2014, v.20, n.1, 103-16.
8. Frith, Uta. Cognitive explanations of autism. Acta Paediatrica, v. 416, p. 63 68, 1996.

9. Gadia C; Tuchman R; Rotta NT, Autismand invasive diseases of neuro development, 2004. Jornal de Ped, supl.83.

10. Muszkat M, Araripe B L, Andrade N C, Muñoz P O L, Mello C B, Neuropsicology of autism. In: Fuentes D, Malloy-Diniz LF, Camargo CHP, Cosenza RM, orgs. Neuropsicologia, teoria e prática, Porto Alegre: Artmed, 2014. 2 ed.cap.13.183-191.

11. Paula C S, Ribeiro S H, Fombonnle E, Mercadante M T. Briefreport: prevalence of pervasive developmental disorder in Brazil: a pilotstudy. Autism developmental disord. Pubmed, 2011.41(12):1738-42.

12. Pereira, Alessandra; Riesgo, Rudimar S.; Wagner, Mario B. Childhood autism: translation and validation of the Childhood Autism Rating Scale for use in Brazil. Jornal de Pediatria, v. 84, no 6, p. 487-494, 2008.

13. Pimentel AGL, Fernandes FDM, The teachers' point of view with children of autism spectrum, Audiol. Common Res. 2014;19(2):171-8.

14. Rapin, Isabelle; DUNN, Michelle. Language disorders in children with autism.Seminars in Pediatric Neurology, v. 4, n. 2, p. 86-92, 1997.

15. Rapin, Isabelle; Tuchman, Roberto F. Autism: definition, neurobiology, screening, diagnosis. Pediatric Clinics of North America, v. 55, p. 1129 1146, 2008.

16. Rodriguez IR, Saldaña D, Moreno JF, Support inclusion and special education teacher's atitude toward the educaction of students with autismo spectrum disordes. Autism Res. Treatment.2012; 2012:259468.

17. Rotta NT, Ohlweiler L, Riesgo RS (Orgs.)Learning Disorders, Neurobiological and Multidisciplinary Approach. 2 ed-Porto Alegre; Artmed, 2016.

18. Rutter, M. L. (2011). Progress in understanding autism: 2007 - 2010. Journal of Autism and Developmental Disorders, 41, 395 - 404.

19. Schwartzman, J. S.; Araújo, C. A. (Org.). Autism Spedtrum Disorders (São Paulo: Memnon Edições Científicas, 2011. v. 6, p.65-111.

20. Vigostsky, L. S. The social formation of the mind: the development of higher psychological processes. Translated, José Cipolla Neto, Luís Silveira Menna Barreto e Solange Castro Afeche. 6. ed. São Paulo: Martins. Fontes, 2007.

21. Virués-Ortega, J. (2010). Applied behavior analytic intervention for autism in earlychildhood: metaanalysis, meta-regression and dose-response metaanalysis of multiple outcomes. Clinical Psychology Review, 30(4), 387-399. 